\title{
Simultaneous adjustment of the main chemical variables to fine-tune the porosity of carbon xerogels
}

\author{
Natalia Rey-Raap, J. Angel Menéndez, Ana Arenillas* \\ Instituto Nacional del Carbón, CSIC, Apartado 73, 33080 Oviedo, Spain
}

\begin{abstract}
The objective of this study was to assess the effect of the resorcinol-formaldehyde molar ratio of precursor solutions with $\mathrm{pH}$ values ranging from 5.0 to 7.0 and dilution ratios between 5 and 10 upon the final porous properties of carbon xerogels synthesized by microwave heating, using an optimal design of response surface methodology. It was found that when the resorcinol-formaldehyde molar ratio was decreased the microporosity was enhanced as the addition reaction was favored. Hence, the micropore volume of carbon xerogels not only depends on the conditions used during carbonization, but also on the synthesis conditions. Mesoporosity was also increased when the resorcinol-formaldehyde molar ratio decreased while macroporosity was only influenced by the initial $\mathrm{pH}$ of the precursor solutions. The simultaneous variations of the three chemical variables allowed an exhaustive control of the final porous properties of carbon xerogels, which exhibited pore sizes and pore volumes that could not be obtained by modifying just the $\mathrm{pH}$ and the dilution ratio.
\end{abstract}

\section{Introduction}

Carbon gels are porous materials obtained by the polymerization of resorcinol with formaldehyde in the presence of a solvent, following Pekala's method [1]. The wet organic gel is then dried and carbonized in order to obtain the carbon gel. The final

*Corresponding author. E-mail: aapuente@incar.csic.es (A. Arenillas)

Tel. +34985119090

Fax +34985297662 
porous properties of these materials can be tailored by modifying the variables of the different stages of production: polymerization, drying and pyrolysis.

The $\mathrm{pH}$, type of solvent, the concentration of reagents and the temperature and time of the synthesis are some of variables to take into consideration in the polymerization process [2]. Regarding the drying stage, three main types of drying methods can be found in the literature: supercritical drying, freeze-drying and evaporative drying, which give rise to aerogels, cryogels and xerogels, respectively [3-7]. The use of one or another method leads to materials with different properties as shrinkage produced by the removal of the solvent in the case of evaporative drying is much greater than in the other drying processes, and hence, a less developed porous structure is obtained [8,9]. Besides the conditions selected for the synthesis process and the type of drying used, certain final properties can also be modified by the carbonization process. For example, the volume of micropores can be enhanced by adjusting the time, temperature, gas type and gas flow rate used for the carbonization [10-14].

However, the variables that play a role in the polymerization process are the ones that have the greatest influence on the final properties of carbon gels and are therefore the main focus of attention in this work. Previous studies have reported that the final properties are not greatly influenced by the time of synthesis provided that the time is long enough for crosslinking and secondary reactions to take place [15-17]. Furthermore, it has also been reported that the final porous properties are not modified by setting the temperature of synthesis between 75 and $85^{\circ} \mathrm{C}$ [17]. Hence, carbon gels with accurately controlled porous properties can be synthesized by modifying the concentrations of the reagents: resorcinol, formaldehyde, solvent and catalyst. These 
concentrations are reported in the literature to be related to the $\mathrm{pH}$ of the precursor solution, the dilution ratio and the molar ratio between the resorcinol and the formaldehyde. The influence of the $\mathrm{pH}$ of the precursor solution on the final properties of the carbon gel is one of the most studied variables. General speaking, a decrease in the $\mathrm{pH}$ favours the formation of larger pores [5, 18-21]. On the other hand, an increase in the amount of water leads to a structure with a few weakly branched clusters. The mechanical strength of these materials is low, and therefore, during drying they undergo further contraction, resulting in materials with a smaller volume of pores $[5,8,18,20$, 22].

Formaldehyde is responsible for the crosslinking between clusters that takes place during the gelation and ageing steps. An excess of formaldehyde, i.e. lower resorcinol/formaldehyde molar ratio, could lead to the formation of a high number of crosslinkages that could eventually cause a collapse of the pore structure. On the other hand, an amount of formaldehyde below the stoichiometric value could prevent the precursor solution from reaching the gelation point or could lead to a weakly branched structure leading to enhanced shrinkage during drying [11]. Accordingly, some authors state that the resorcinol/formaldehyde molar ratio should be between 0.4 and 0.7 [11, 20]. However, Maldonado-Hódar et al. have reported that a higher range can be used, e. g., from 0.33 to 1.0. They found out that a decrease in the resorcinol/formaldehyde molar ratio to below the stoichiometric value (i.e. 0.5 ) led to an increase in the volume of micropores and to a decrease in the volume of macropores, while no variations in the volume of mesopores were observed [23]. Other authors were able to synthesize aerogels with a resorcinol/formaldehyde molar ratio below 0.4 when acidic conditions were fixed. The materials obtained hardly shrank and exhibited a well-developed mesoporous structure [24]. However, it must be noted that these studies were performed 
on aerogels that, in general, are materials which, depending on the drying method used, barely suffer contractions during drying. Nonetheless, different trends due to the influence of the resorcinol/formaldehyde molar ratio on the final porous properties can be found when other drying methods, such as evaporative drying, are applied. For this reason, such trends need to be studied in depth.

In order to reduce the production costs of carbon gels and to promote the marketing of these materials, microwave assisted and evaporative drying should be employed. Microwave technology for the production of carbon xerogels is a cost-effective process since the processing time is considerably reduced and only one device and moderate conditions are needed. However, to accurately tailor the final porous properties of carbon xerogels, the effect of adjusting the chemical variables involved in the synthesis process needs to be fully understood.

In this work, the influence of the resorcinol/formaldehyde molar ratio on the final porous properties of carbon xerogels obtained from precursor solutions with different values of $\mathrm{pH}$ and dilution ratios was studied. In order to evaluate any possible synergy between these three main chemical variables and to enhance the control of the porosity of the materials, the response surface methodology was applied to four response variables: the volume of micropores, mesopores and macropores, and the overall porosity.

\section{Experimental}

\subsection{Synthesis of organic and carbon xerogels}


Organic xerogels were synthesized by the polycondensation of resorcinol (R) and formaldehyde (F) using deionized water as solvent. Resorcinol (Indspec, 99\%) was first dissolved in deionized water in an unsealed glass beaker under magnetic stirring. After dissolution, formaldehyde (Ercros, 37wt. \% in water, stabilized by $10-15 \%$ methanol) was added and the mixture was stirred until a homogeneous solution was obtained. All the xerogels were synthesized from $200 \mathrm{ml}$ of precursor solution and the final $\mathrm{pH}$ value was adjusted by adding sodium hydroxide. The amount of resorcinol, formaldehyde and water used for each sample depended on the resorcinol/formaldehyde molar ratio $(\mathrm{R} / \mathrm{F})$ and the dilution ratio (D) selected. The dilution ratio parameter is defined as the molar ratio between the total solvent and reactants. Total solvent refers to the water and methanol contained in the formaldehyde and the deionized water that is added, whilst the term reactants refers to the resorcinol and formaldehyde.

The ranges of $\mathrm{pH}$ values of the precursor solutions were selected on the basis of previous experimental results [22]. Samples with a $\mathrm{pH}$ greater than 7.0 are exclusively microporous materials while samples with a $\mathrm{pH}$ value lower than 5.0, display averages pore sizes greater than 200nm. Most of the applications in which carbon xerogels are promising materials require averages pore sizes below $200 \mathrm{~nm}$. Consequently, in this study the $\mathrm{pH}$ range of the precursor solutions was fixed between 5.0 and 7.0. The range of values for the dilution ratio was selected on the basis of a previous study in which it was reported that, for all the $\mathrm{pH}$ values, when the dilution ratio was decreased to below 5 or increased to above 10 , the materials obtained had a poorly developed porous structure. The maximum value for the resorcinol/formaldehyde molar ratio was selected on the basis of the porous properties of the xerogels, i. e., the molar ratio was increased gradually until the materials obtained presented a non-porous structure. Some xerogels 
did not reach the gelation point for certain dilution ratios when the resorcinol/formaldehyde molar ratio was fixed below 0.1. Hence, the resorcinol/formaldehyde molar ratio was varied from 0.1 to 1.0 .

Each precursor solution was placed in a microwave oven at $85^{\circ} \mathrm{C}$ for $3 \mathrm{~h}$, to allow gelation and ageing to be completed [17]. After the formation of the polymeric structure, excess water was eliminated by continuing to heat the gel in the microwave oven until a mass loss of over $50 \%$ was achieved. The drying step lasted 1-2 hours depending on the final pore structure of the material.

After drying, the xerogels were carbonized at $700{ }^{\circ} \mathrm{C}$ under a nitrogen flow of 500 $\mathrm{ml} / \mathrm{min}$ in a horizontal tubular furnace, using the same procedure as in previous works [10]. The residence time was 2 hours and the heating rate was set at $50^{\circ} \mathrm{C} / \mathrm{min}$.

\subsection{Sample characterization}

The porous properties of the carbon xerogels were characterized by nitrogen adsorptiondesorption isotherm analysis and by a mercury porosimetry technique, performed at $196{ }^{\circ} \mathrm{C}$ using a Micromeritics Tristar 3020 instrument and in a Micromeritics AutoPore IV, respectively. Prior to each analysis, all the samples were outgassed at $120^{\circ} \mathrm{C}$ and 0.1 mbar for $8 \mathrm{~h}$ using a Micromeritics VAcPrep 061. The micropore volume was calculated by applying the Dubinin-Raduskevich method to the nitrogen adsorptiondesorption isotherms. Pore volume measurements by nitrogen adsorption are not precise enough for samples with large mesopores. For this reason, mercury porosimetry was used as a complementary technique to determine the volume of mesopores and 
macropores and the percentage of porosity. Analysis of mercury porosimetry was based on Washburn's intrusion theory.

\subsection{Experimental design}

Response Surface Methodology (RSM) was applied to the characterization results in order to optimize the microwave-assisted synthesis of carbon xerogels. By using a suitable Design Of Experiments (DOE), namely D-optimal, it was possible to reduce the number of experiments needed and assess the possible synergy between the variables studied: the $\mathrm{pH}$, the dilution ratio (D) and the resorcinol/formaldehyde molar ratio $(\mathrm{R} / \mathrm{F})$. An optimal design requiring 70 experimental points, covering all the possible $\mathrm{pH}-\mathrm{D}-\mathrm{R} / \mathrm{F}$ combinations along with repeated experimental runs, was employed to obtain a statistical model that would adequately fit the experimental results. The volume of micropores, mesopores and macropores and the overall porosity were selected as the responses of the system. The design matrix was generated by using a Design-Expert 9.0 Trial version from Stat-Ease Inc.

\section{Results}

Carbon xerogels were synthesized with different $\mathrm{pH}$, dilution ratio and $\mathrm{R} / \mathrm{F}$ molar ratio values. These values ranged from 5.0 to 7.0 , from 5 to 10 and from 0.1 to 1.0 , respectively. All the carbon xerogels were characterized from the point of view of their porous structure. Figure 1 illustrates the pore size distribution of some of the samples obtained by mercury porosimetry. 

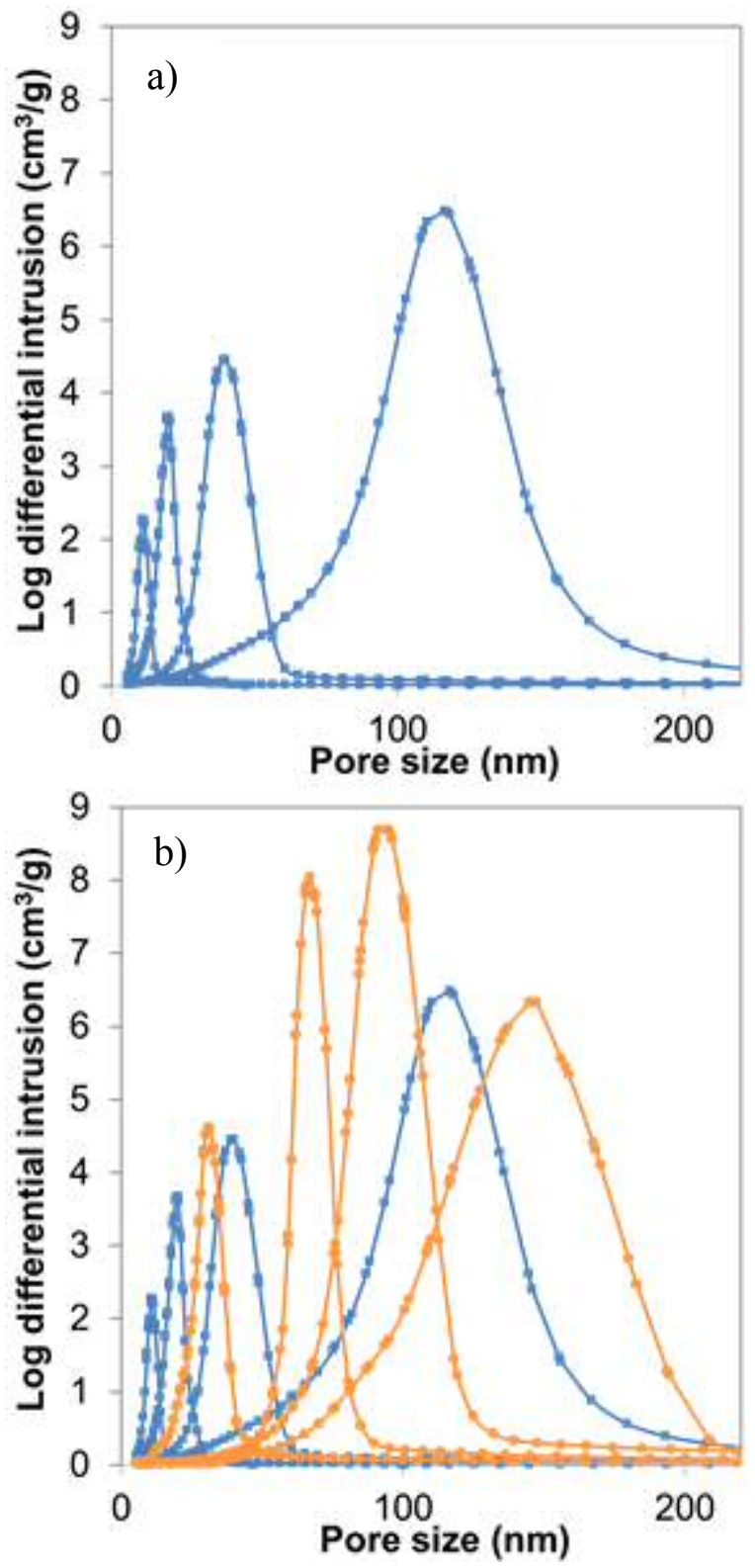

Figure 1. Pore size distribution of carbon xerogels prepared using (a) different initial $\mathrm{pHs}$ and the most commonly used dilution ratio (i.e. 5.7) and the stoichiometric $\mathrm{R} / \mathrm{F}$ molar ratio (i.e. 0.5) and (b) the pore size distribution of carbon xerogels prepared by simultaneous adjustment of the $\mathrm{pH}$, dilution ratio and $\mathrm{R} / \mathrm{F}$ molar ratio

Figure 1a includes carbon xerogels prepared from precursor solutions with the dilution ratio and the $\mathrm{R} / \mathrm{F}$ molar ratio most frequently used by other authors, i. e., 5.7 and 0.5 , respectively, but with different initial pHs: 6.5, 6.0, 5.5, 5.0. As can be seen from Figure 
1, the pore size distributions show a clear difference in shape and in average pore size depending on the initial $\mathrm{pH}$ value, ranging from less than $20 \mathrm{~nm}$ to pore sizes greater than $100 \mathrm{~nm}$. Furthermore, as the $\mathrm{pH}$ decreases, not only does the pore size increase but also the volume of the pores. However, there is a wide range of pore sizes and pore volumes that cannot be achieved by only changing the $\mathrm{pH}$ of the precursor mixture. It is also necessary to vary the dilution ratio and the $\mathrm{R} / \mathrm{F}$ molar ratio.

As can be seen in Figure 1b, by modifying simultaneously these three chemical variables, materials with intermediate pore size distributions that cannot be obtained by just modifying the $\mathrm{pH}$ of the precursor solution can be synthesized. Furthermore, such samples not only have an intermediate average pore size but also a higher pore volume. This demonstrates that complete control of the final porous properties of carbon xerogels depends to a great extent on the $\mathrm{pH}$, the dilution ratio and the $\mathrm{R} / \mathrm{F}$ molar ratio.

\subsection{Statistical analysis}

Statistical analyses were performed using response surface methodology (RSM). The implementation of RSM allows the interaction between the $\mathrm{pH}$, the dilution ratio and the $\mathrm{R} / \mathrm{F}$ molar ratio and their effect on the main porous properties to be evaluated with a minimum number of experiments. In order to determine whether the model selected was sufficiently significant to fit the experimental results, an analysis of variance (ANOVA) was applied to each of the four variables selected as responses: volume of micropore, mesopore and macropore and percentage of porosity. The significance of each input variable, i.e., $\mathrm{pH}, \mathrm{D}$ and $\mathrm{R} / \mathrm{F}$, and their possible interaction was determined by assessing the $p$-value. If the $p$-values turn out to be smaller than 0.05 , the corresponding variable will have a significant effect on the response. 


\subsubsection{Micropore volume}

The micropore volume values for all carbon xerogels synthesized using the selected $\mathrm{pH}$ $\mathrm{D}-\mathrm{R} / \mathrm{F}$ combination were adjusted to a cubic function. The correlation coefficient value $\mathrm{R}$-squared was 0.80 , indicating that the calculated results were in good agreement with those obtained experimentally. The results of the ANOVA applied to the microporosity are summarized in Table S1 in the supporting information. The data obtained by employing a least square technique indicate that the model is significant for microporosity. Moreover, the quadratic term of $\mathrm{R} / \mathrm{F}$ is the most significant model term based on the $\mathrm{p}$-value $(\mathrm{P}<0.005)$, indicating that modification of the other two chemical variables, $\mathrm{pH}$ and $\mathrm{D}$, has no effect on the influence of the micropore volume.

Three-dimensional (3D) surface plots were constructed on the basis of the model equations obtained for different values of $\mathrm{R} / \mathrm{F}$ molar ratio, representing the response surface curves of two of the independent variables, $\mathrm{pH}$ and $\mathrm{D}$, versus the dependent variable, the volume of micropores (Figure 2). The 3D plots show the evolution of the micropore volume in the samples with a $\mathrm{pH}$ value between 5.0 and 7.0 and a dilution ratio between 5 and 10 , when the $\mathrm{R} / \mathrm{F}$ molar ratio is fixed at $0.3,0.5$ and 0.7 , respectively. 

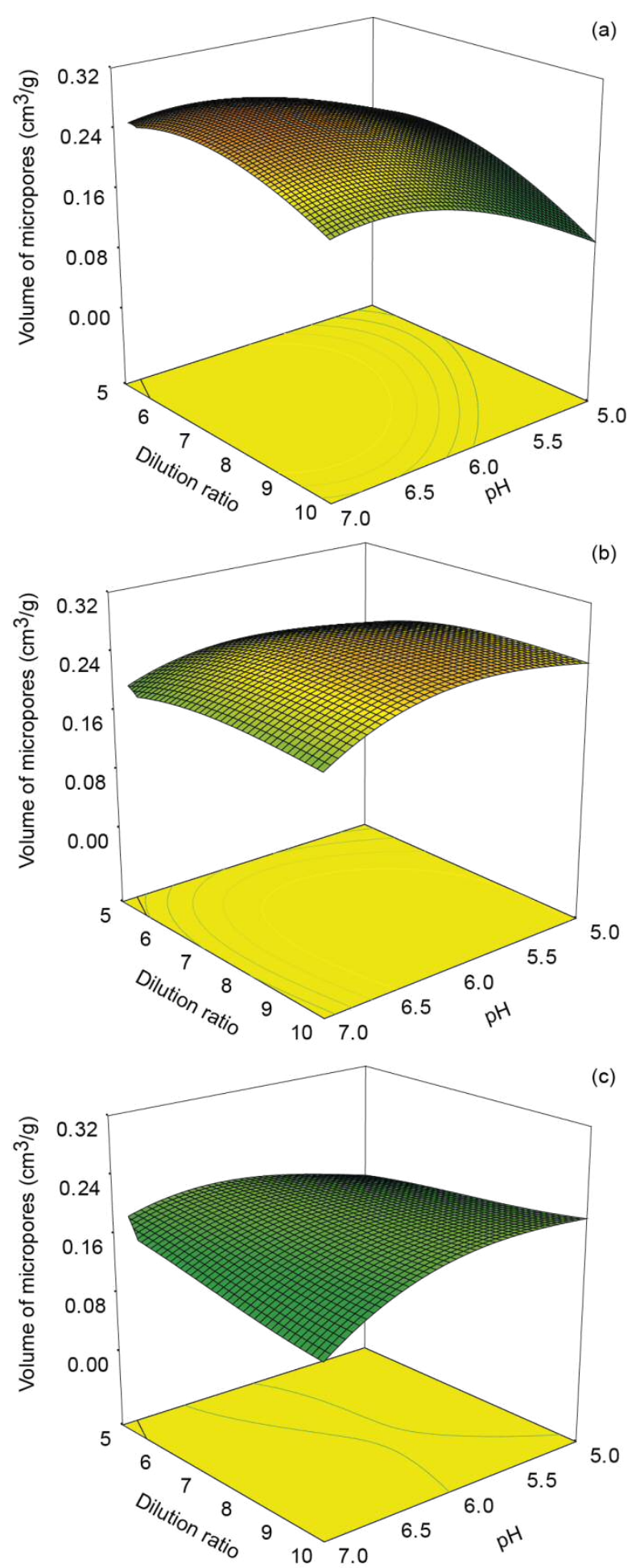

Figure 2. Three-dimensional surfaces representing the effect of the $\mathrm{pH}$ and dilution ratio on the microporosity of carbon xerogels when setting the $\mathrm{R} / \mathrm{F}$ molar ratio to 0.3 (a), 0.5

(b) and 0.7 (c) 
Regardless of the $\mathrm{R} / \mathrm{F}$ molar ratio, the $\mathrm{pH}$ and the dilution ratio hardly affect the micropore volume within the range studied. However, if Figures $2 \mathrm{a}, 2 \mathrm{~b}$ and $2 \mathrm{c}$ are compared, clear differences can be seen when the $\mathrm{R} / \mathrm{F}$ molar ratio is modified. By selecting the stoichiometric value (i.e. 0.5), all the carbon xerogels exhibit a similar micropore volume value of around $0.25 \pm 0.01 \mathrm{~cm}^{3} / \mathrm{g}$. An increase in the $\mathrm{R} / \mathrm{F}$ molar ratio from 0.5 to 0.7 gives rise to a slight decrease in the volume of micropores from $0.25 \pm$ 0.01 to $0.20 \pm 0.03 \mathrm{~cm}^{3} / \mathrm{g}$, while a large increase to above 0.7 leads to materials with a poorly developed microporous structure which display an average micropore volume of $0.15 \pm 0.02 \mathrm{~cm}^{3} / \mathrm{g}$. The micropore volume is enhanced when an $\mathrm{R} / \mathrm{F}$ molar ratio below the stoichiometric value is selected. The highest micropore volume value is obtained by adjusting the $\mathrm{R} / \mathrm{F}$ molar ratio to 0.2 . However, below this value, the micropore volume again decreases to values of about $0.15 \pm 0.02 \mathrm{~cm}^{3} / \mathrm{g}$. The evolution of the micropore volume of the carbon xerogel over the entire range of $\mathrm{pH}-\mathrm{D}-\mathrm{R} / \mathrm{F}$ combinations studied is shown in the animation file in the supporting information.

To the best of our knowledge, most of the publications until now have indicated that the development of the micropores takes place within the nodules during the pyrolysis step. However, in this study, variations in the volume of micropores occurred when the R/F molar ratio was modified. It would seem appropriate therefore to evaluate the variation of microporosity in the organic RF xerogel counterparts in order to see whether the volume of micropores is also influenced by the polymerization reactions. Figure 3 shows the evolution of the micropore volume when the $\mathrm{pH}$ and the dilution ratios of organic xerogels synthesized from precursor solutions with $\mathrm{pH}$ values between 5.0 and 7.0 and dilution ratios from 5 to 10 , are modified, while the $\mathrm{R} / \mathrm{F}$ molar ratio is fixed at $0.3,0.5$ and 0.7 , respectively. The micropore volume of the organic samples follows the 
same trend as the micropore volume of the carbonized samples (Figure 2), i.e., the microporosity decreases when the $\mathrm{R} / \mathrm{F}$ molar ratio is increased.
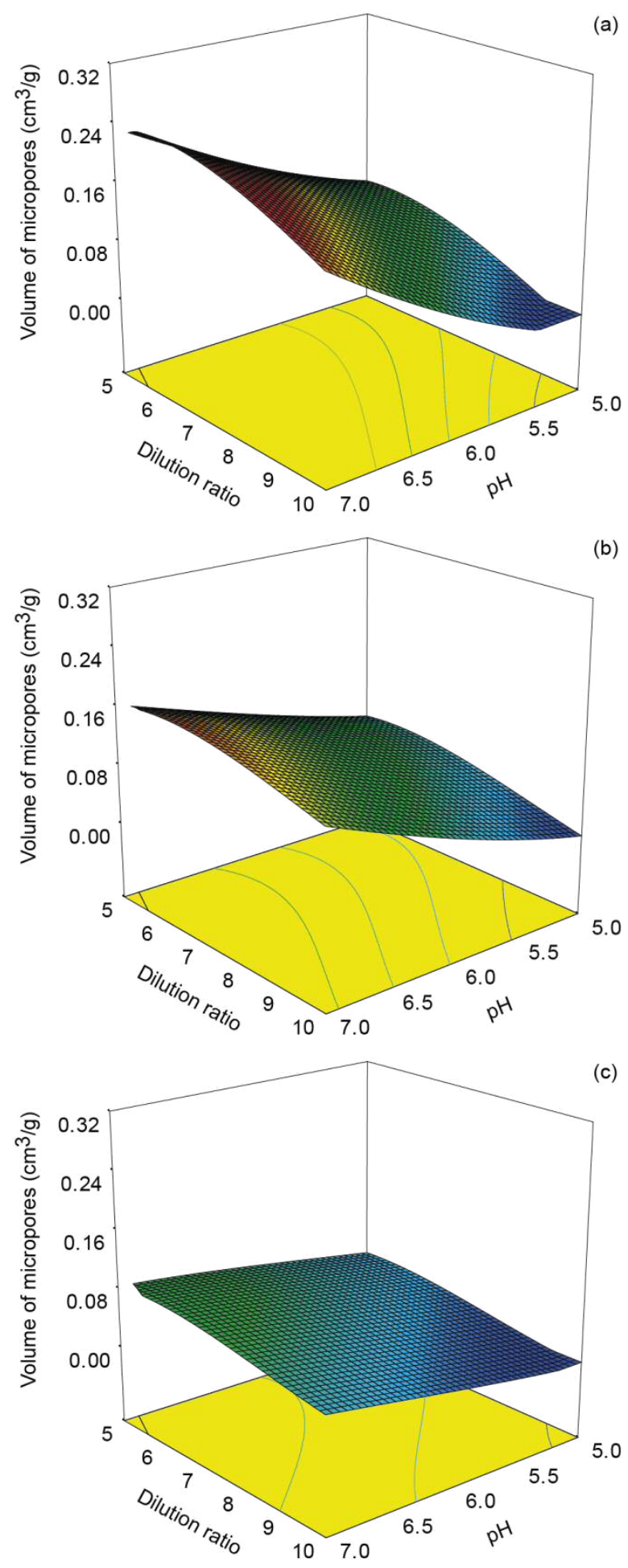

Figure 3. Three-dimensional surfaces representing the effect of the $\mathrm{pH}$ and dilution ratio on the microporosity of organic xerogels when the $\mathrm{R} / \mathrm{F}$ molar ratio is set to 0.3 (a), 0.5

(b) and 0.7 (c) 
The extent of the improvement or increase in microporosity during the carbonization process differs greatly when the $\mathrm{R} / \mathrm{F}$ molar ratio is modified. Organic xerogels synthesized from precursor solutions at the $\mathrm{R} / \mathrm{F}$ stoichiometric value and an $\mathrm{R} / \mathrm{F}$ molar ratio lower than the stoichiometric value display similar micropore volumes while, when the $\mathrm{R} / \mathrm{F}$ molar ratio is adjusted to above the stoichiometric value, the resulting organic xerogels exhibit a poorly developed microporosity. During the pyrolysis, the microporosity of these materials is enhanced up to values close to those obtained for organic xerogels with a low $\mathrm{R} / \mathrm{F}$ molar ratio. Considering that these are carbonized samples, the micropore volume is still low, even though an $86 \%$ increase is achieved. In the samples with lower values of $\mathrm{R} / \mathrm{F}$ molar ratio, the increase in microporosity is about $50 \%$. These results show that, regardless of the increase in micropore volume from carbonization, the microporosity of the carbon xerogels not only depends on the conditions established during the carbonization, but also on the microporosity of the organic counterparts and, consequently, on the synthesis conditions.

\subsubsection{Mesopore Volume}

The mesopore volume values for all the samples synthesized using the $\mathrm{pH}-\mathrm{D}-\mathrm{R} / \mathrm{F}$ combinations studied were adjusted to a cubic function with an R-squared value of 0.76 . The results of the ANOVA applied to mesoporosity are presented in Table S2. The data obtained by employing a least square technique indicate that the model is significant for mesoporosity. Moreover, the quadratic and cubic terms of $\mathrm{pH}$ and the $\mathrm{R} / \mathrm{F}$ are significant model terms based on the $\mathrm{p}$-value $(\mathrm{P}<0.005)$. The interactions between the three chemical variables are not significant, indicating that modification of one of these variables has no effect on the influence of the other two. 
Three-dimensional surface plots constructed according to the model equations obtained for different values of the R/F molar ratio are shown in Figure 4. The 3D plots show the evolution of the mesopore volume of the samples with a $\mathrm{pH}$ value between 5.0 and 7.0 and a dilution ratio between 5 and 10 , when the $\mathrm{R} / \mathrm{F}$ molar ratio is set to 0.5 and 0.2 , respectively, for the carbonized samples and their corresponding organic counterparts.
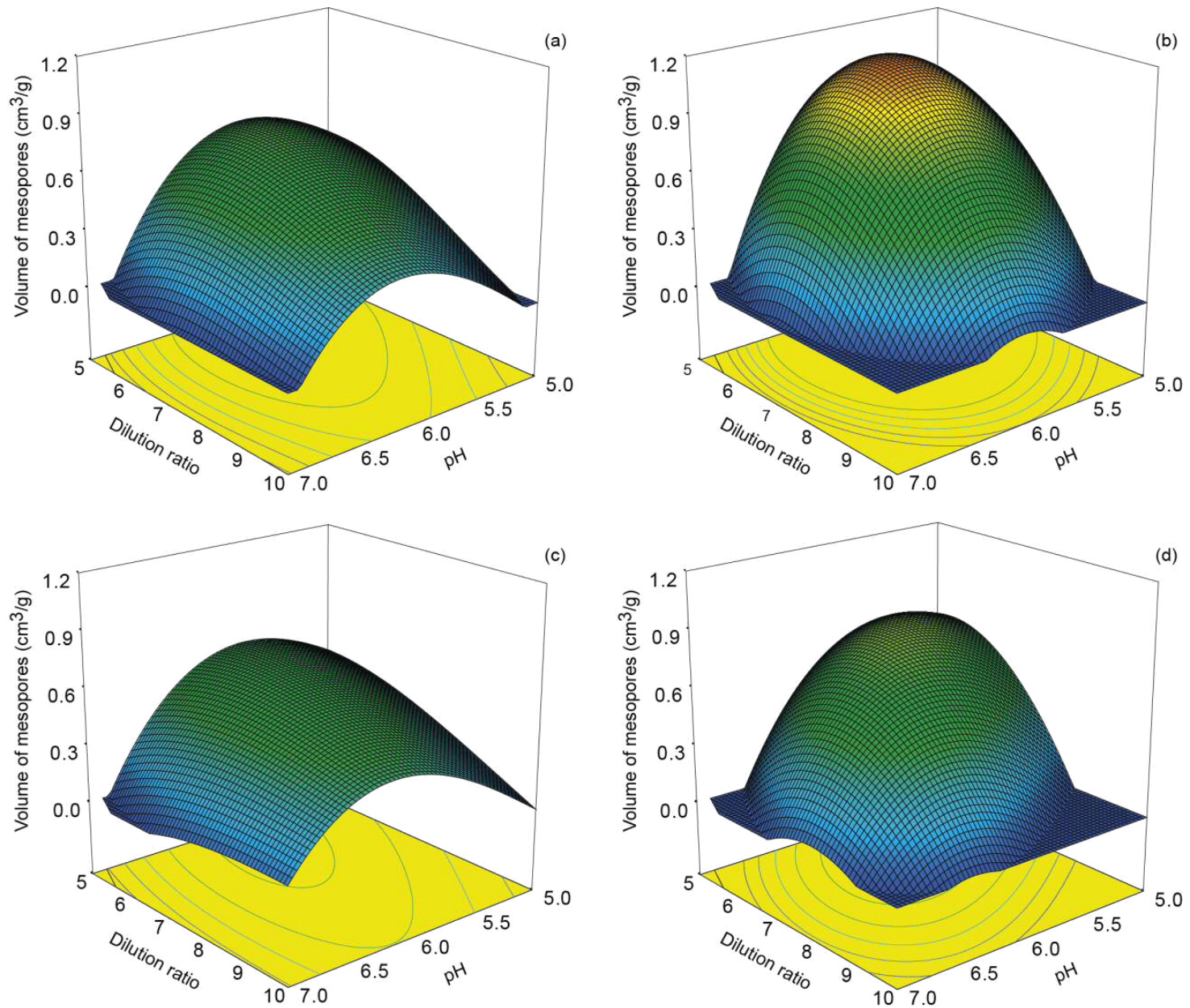

Figure 4. Three-dimensional surfaces representing the effect of the $\mathrm{pH}$ and dilution ratio on the mesoporosity of carbon xerogels when the R/F molar ratio is fixed at 0.5 (a) and 0.2 (b) and of organic xerogels when the R/F molar ratio is fixed at 0.5 (c) and 0.2 (d)

In Figure 4a a maximum mesopore volume value of about $0.65 \pm 0.05 \mathrm{~cm}^{3} / \mathrm{g}$ is obtained 
by adjusting the $\mathrm{pH}$ between 5.6 and 6.0 and the dilution ratio between 5.5 and 7.0. A decrease in the $\mathrm{R} / \mathrm{F}$ molar ratio to below the stoichiometric value leads to an increase in the mesopore volume, especially at low $\mathrm{pH}$ and dilution ratio values within the range studied. In Figure $4 \mathrm{~b}$ a maximum mesopore volume value of around $1.1 \pm 0.05 \mathrm{~cm}^{3} / \mathrm{g}$ can be clearly observed. By increasing the $\mathrm{R} / \mathrm{F}$ molar ratio to above 0.5 the volume of mesopores decreases to values below $0.1 \pm 0.05 \mathrm{~cm}^{3} / \mathrm{g}$. The evolution of the mesopore volume of the carbon xerogel over the entire range of $\mathrm{pH}-\mathrm{D}-\mathrm{R} / \mathrm{F}$ combinations studied is shown in the animation file in the supporting information.

Most of the published works relating to the carbonization of resorcinol-formaldehyde gels state that mesoporosity is affected by the synthesis conditions while it remains almost invariable during carbonization. This statement is in agreement with the results shown in Figure $4 \mathrm{a}$ and 4c. The organic samples and their corresponding carbonized counterparts obtained from precursor solutions with the stoichiometric $\mathrm{R} / \mathrm{F}$ molar ratio value exhibit a similar mesoporosity. In other words, during the carbonization process the mesopore volume is barely modified.

However, in Figure $4 \mathrm{~b}$ and $4 \mathrm{~d}$ it can be clearly observed that, when the R/F molar ratio is fixed at below the stoichiometric value, the volume of mesopores increases during carbonization. The organic samples presented in Figure $4 \mathrm{~d}$ have an average maximum volume value of $0.82 \pm 0.05 \mathrm{~cm}^{3} / \mathrm{g}$ which, after carbonization, increases to $1.1 \pm 0.05$ $\mathrm{cm}^{3} / \mathrm{g}$ (Figure $\left.4 \mathrm{~b}\right)$.

\subsubsection{Macropore volume}


The macropore volume values of the synthesized samples were fitted to a cubic function with a correlation coefficient value of 0.80 . The results of the ANOVA applied to the macropore volume are presented in Table S3 in the supporting information. The data obtained by applying the least square technique indicate that the model is significant for macroporosity. As regards the chemical variables, only the $\mathrm{pH}$ term appears to be significant. The dilution ratio, the $\mathrm{R} / \mathrm{F}$ molar ratio and the interaction between the three variables are not significant model terms within the range of $\mathrm{pH}-\mathrm{D}-\mathrm{R} / \mathrm{F}$ combinations studied. These results were as expected considering that the initial conditions of the precursor mixtures were selected on the basis of the average pore size, in order to cover the entire range of mesoporosity and a small range of macroporosity (average pore size from a few nanometers to $200 \mathrm{~nm}$ ). Hence, the range of study as regards macroporosity is not wide enough for variations to be detected when the dilution ratio and the $\mathrm{R} / \mathrm{F}$ molar ratio are modified.

Three-dimensional (3D) surface plots were constructed on the basis of the model equations obtained for different values of the $\mathrm{R} / \mathrm{F}$ molar ratio, representing the response surface curves of the $\mathrm{pH}$ and $\mathrm{D}$ versus the macropore volume (Figure 5). The 3D plots show the evolution of the macropore volume of the samples with a $\mathrm{pH}$ value between 5.0 and 7.0 and a dilution ratio between 5 and 10 , when the R/F molar ratio is set to 0.4 , 0.5 and 0.8 , respectively. 

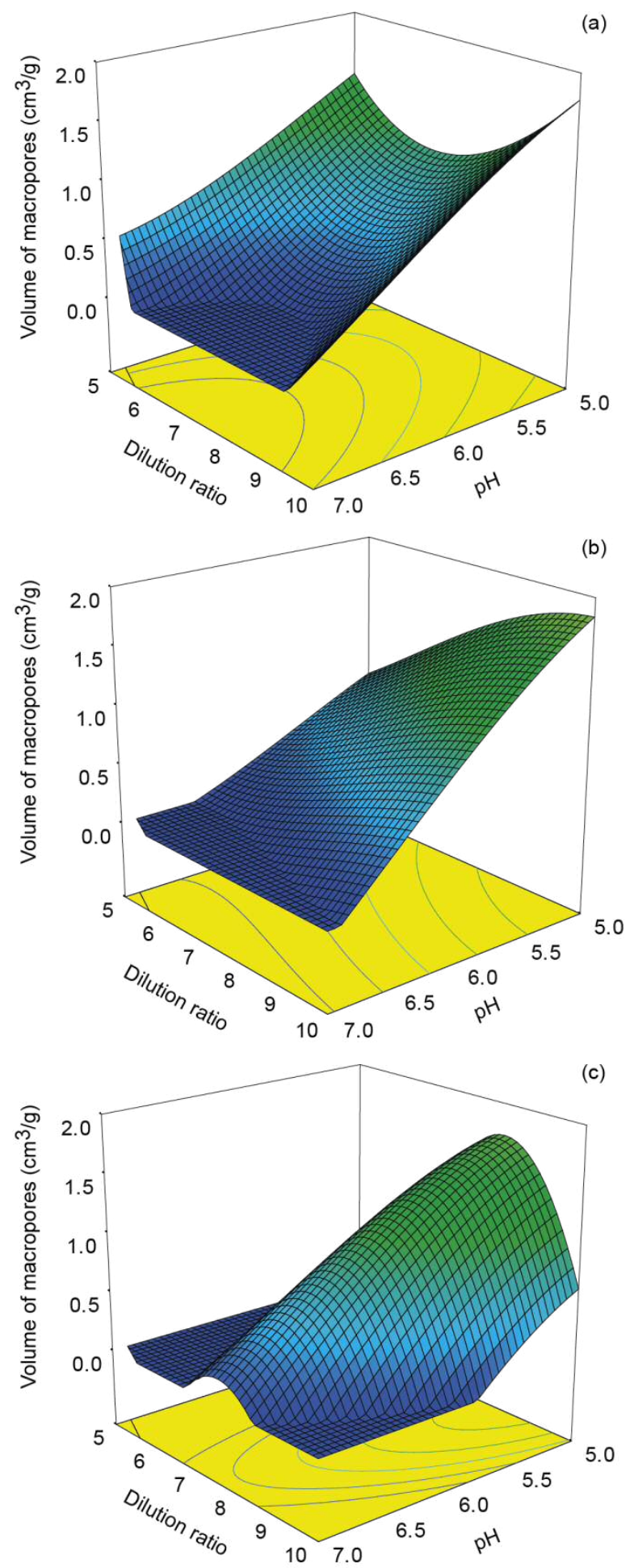

Figure 5. Three-dimensional surface representing the effect of the $\mathrm{pH}$ and dilution ratio on the macroporosity of carbon xerogels when the $\mathrm{R} / \mathrm{F}$ molar ratio is fixed at 0.4 (a), 0.5

(b) and $0.8(\mathrm{c})$ 
For all the combinations of $\mathrm{pH}-\mathrm{D}-\mathrm{R} / \mathrm{F}$ studied the macropore volume ranges from $0.0 \pm$ $0.04 \mathrm{~cm}^{3} / \mathrm{g}$ to $1.9 \pm 0.04 \mathrm{~cm}^{3} / \mathrm{g}$. Macroporous materials can be synthesized by adjusting the $\mathrm{pH}$ to below 5.5 and the dilution ratio up to 7 , within a $\mathrm{R} / \mathrm{F}$ molar ratio range of between 0.4 and 0.8 . An increase in the R/F molar ratio to above 0.8 causes a decrease in the volume of macropores to below $0.3 \pm 0.02 \mathrm{~cm}^{3} / \mathrm{g}$. The macroporosity also decreases when the $\mathrm{R} / \mathrm{F}$ molar ratio is lower than 0.4 , since under these synthesis conditions, the materials obtained are in the mesoporosity range.

\subsubsection{Porosity}

The porosity values of all carbon xerogels were adjusted to a quadratic function with an R-squared value of 0.80 . The results of the ANOVA applied to porosity are summarized in Table S4. The data obtained by applying the least square technique indicate that the model is significant for porosity. The $\mathrm{pH}$, the dilution ratio and the quadratic term for the three chemical variables are also significant terms. Moreover, the interaction between the dilution ratio and both the $\mathrm{pH}$ and the $\mathrm{R} / \mathrm{F}$ molar ratio are significant, indicating that modification of one of the variables affects the influence of the other two on the porous properties of the material.

Three-dimensional surface plots constructed according to the model equations obtained for different values of $\mathrm{R} / \mathrm{F}$ molar ratio are shown in Figure 6 . The $3 \mathrm{D}$ plots show the evolution of the porosity of carbon xerogels synthesized from precursor solutions with a $\mathrm{pH}$ value of between 5.0 and 7.0 and a dilution ratio of between 5 and 10, when the R/F molar ratio is fixed at 0.5 and 0.3 , respectively. 

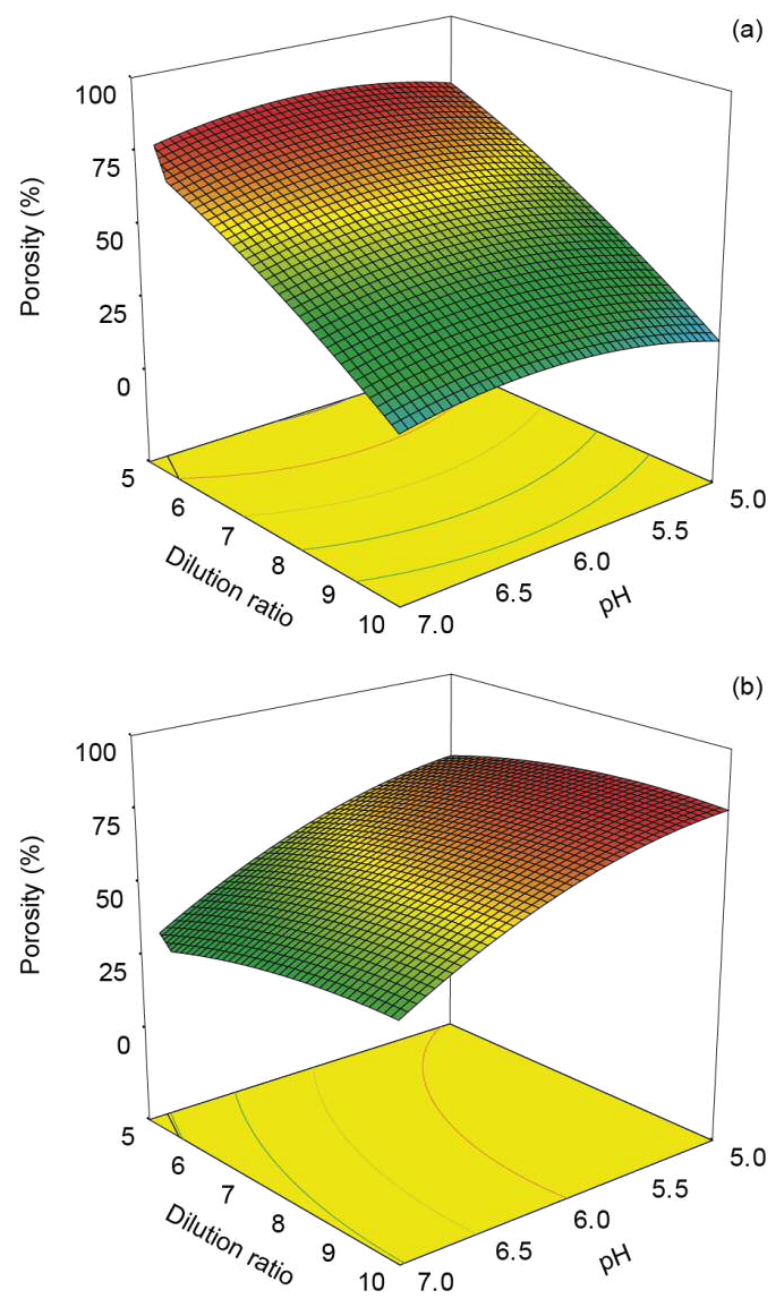

Figure 6. Three-dimensional surface representing the effect of the $\mathrm{pH}$ and dilution ratio on the porosity of carbon xerogels when the R/F molar ratio is fixed at 0.5 (a) and 0.2

(b)

Within the range of $\mathrm{pH}-\mathrm{D}-\mathrm{R} / \mathrm{F}$ combinations studied, the materials obtained exhibit a maximum porosity of $80 \%$. Materials with higher values of porosity can be found in the literature [5]. However, in this study the $\mathrm{pH}$ and the dilution ratio of the precursor solutions were selected so that most of the materials would be in the mesoporosity range, which would then display lower values of porosity. Higher porosities up to ca. $90 \%$ could be achieved by fixing lower $\mathrm{pH}$ values, but then the materials would fall 
within the range of large macroporosity and, consequently, outside the scope of this study.

Regardless of the R/F molar ratio selected, the highest porous materials are obtained when the $\mathrm{pH}$ is set to below 5.6. Although variation of the $\mathrm{R} / \mathrm{F}$ molar ratio does not have a direct influence on the porosity, it causes a change in the range of the dilution ratio necessary to obtain highly porous materials. In fact, as the $\mathrm{R} / \mathrm{F}$ molar ratio is increased from 0.1 to 0.5 the dilution ratio shifts to a range of higher values in order for materials with a well-developed porosity to be obtained. The porosity of samples synthesized from precursor solutions prepared with an $\mathrm{R} / \mathrm{F}$ molar ratio greater than 0.5 decreases and displays porosity values below $40 \%$ when the $\mathrm{R} / \mathrm{F}$ molar ratio is at its maximum value.

\section{Discussion}

Several authors have reported that the carbonization process involves the breaking of C$\mathrm{O}$ bonds at low temperatures and the breaking of $\mathrm{C}-\mathrm{H}$ bonds at high ones $[23,25]$. The breakage of bonds leads to the rearrangement of molecules resulting in a stable structure [18]. Some walls separating individual micropores will break resulting in the enlargement of narrow micropores [14]. On the other hand, the condensation produced during the carbonization process causes a slight shrinkage of the polymeric structure and, consequently, the size of the mesopores and macropores will decrease [21]. Some mesopore sizes will be smaller than $2 \mathrm{~nm}$ and therefore, the volume of these pores will have to be considered as micropores rather than mesopores. Both phenomena contribute to an increase in microporosity during carbonization. Accordingly, the volume of micropores depends to a great extent on the carbonization conditions. 
The results of this study are in good agreement with the above explanation when carbon xerogeles are synthesized from precursor solutions with the stoichiometric value of the $\mathrm{R} / \mathrm{F}$ molar ratio. Under these conditions the variation in microporosity when the $\mathrm{pH}$ and the dilution ratio are modified is negligible. However, when the $\mathrm{R} / \mathrm{F}$ molar ratio is modified the microporosity is enhanced. The increase in microporosity produced by modifying the $\mathrm{R} / \mathrm{F}$ molar ratio can be attributed to the polymerization between resorcinol and formaldehyde.

Initially, resorcinol anions are formed by hydrogen abstraction. These anions are more reactive than resorcinol and promote the addition of formaldehyde to form hydroxymethyl derivatives, which are the monomers necessary for polymerization to occur [9]. At the same time as the addition reaction, condensation occurs. The hydroxymethyl derivatives then lose $\mathrm{OH}$ groups to form benzyl-type cations. Each cation reacts with a benzene ring of another molecule giving rise to a methylene bond [21]. As the reaction proceeds the number of bonds between the rings increases, forming the polymer backbone, which leads to three-dimensional cross-linked polymer clusters or, as defined by other authors, primary particles [26] An increase in the concentration of formaldehyde, i.e. a decrease in the R/F molar ratio, shifts the chemical equilibrium toward the products, increasing the reaction rate [18]. This suggests that the clusters will form and grow faster, i.e., the addition reaction will be promoted, resulting in the formation of more branched clusters. Consequently, carbon xerogels synthesized from precursor solutions with a concentration of formaldehyde higher than the stoichiometrically required amount, display a greater number of highly branched clusters of larger size and therefore, higher micropore volumes could be achieved as 
shown in Figure 2. Another possible reason can be that the over loaded formaldehyde cannot react with resorcinol and remain inside the clusters freely. This unreacted formaldehyde is removed during drying due to its low boiling point. Hence, the place left by these formaldehyde molecules may be the cause of the increased microporosity..

Another point worth mentioning is that the microporosity of the organic counterparts is also influenced by the $\mathrm{pH}$ and the dilution ratio apart from the $\mathrm{R} / \mathrm{F}$ molar ratio. In general, regardless of the $\mathrm{R} / \mathrm{F}$ molar ratio, the micropore volume increases as the $\mathrm{pH}$ and the dilution ratio decrease (Figure 3). The catalyst favours the addition reaction, i.e., the formation of resorcinol anions which are the active sites where formaldehyde is added during the addition reaction and where the formation of the clusters originates [27]. Therefore, increasing the $\mathrm{pH}$ value of the precursor solutions causes the formation of a large number of small clusters interconnected by long necks. Meanwhile, a decrease in the dilution ratio will necessarily result in an increase in the amount of resorcinol and formaldehyde used, leading to a highly branched structure. Nonetheless, the effect of these two chemical variables disappears during the carbonization process, leaving as the only significant chemical variable the $\mathrm{R} / \mathrm{F}$ molar ratio.

The addition of an excess of formaldehyde affects not only the volume of micropores, but also the mesoporous structure. When the molar ratio of resorcinol and formaldehyde is fixed at the stoichiometric value (i. e. 0.5 ) the maximum mesopore volume value is obtained for the combinations of $\mathrm{pH}-\mathrm{D}$ between 5.5 and 6.0 and 5 and 7, respectively. The $\mathrm{pH}$ and $\mathrm{D}$ values for which the maximum mesopore volume values are obtained, are not altered by a decrease in the $\mathrm{R} / \mathrm{F}$ molar ratio below the stoichiometric value. However, the volume is enhanced by $37 \%$ when the molar ratio is fixed at 0.2 . This 
increase in mesoporosity is due to both a decrease in the $\mathrm{R} / \mathrm{F}$ molar ratio and the carbonization process (Figure 4). The excess of formaldehyde not only accelerates the formation and growth of clusters but also creates more interconnections between them, leading to a highly branched structure $[1,18]$. The mechanical strength of the organic xerogels is higher and therefore no shrinkage will occur during drying [8], leaving larger pores than in the case of samples synthesized from a precursor solution with the stoichiometric $\mathrm{R} / \mathrm{F}$ molar ratio. As explained above, during carbonization part of that highly branched structure will break, leading to larger voids and, consequently to a higher mesoporosity. A insufficient amount of formaldehyde will lead to a weakly branched structure whose mechanical strength will not be able to counteract the surface tension created during drying and the material will shrink, resulting in the partial collapse of the structure and a decrease in the mesopore volume [11]. The collapse will be greater if the $\mathrm{R} / \mathrm{F}$ molar ratio is increased, leading to a poor-developed mesoporous structure, especially when the molar ratio exceeds 0.8 .

The macropore volume is not greatly influenced by the $\mathrm{R} / \mathrm{F}$ molar ratio, but large variations are observed due to the initial $\mathrm{pH}$ of the precursor solutions. Previous studies indicate that for $\mathrm{pH}$ values lower than 5.5, macroporous materials are obtained when high dilution ratios are selected [22]. A decrease in the $\mathrm{pH}$ value will lead to the formation of a smaller number of large clusters, resulting in a structure with a higher pore volume that may come within the macroporosity range. The range of $\mathrm{pH}-\mathrm{D}$ combinations used in this study falls outside the range of maximum macroporosity and thus, no large variations in the volume of macropores were observed. 
The porosity of carbon xerogels decreases when the $\mathrm{R} / \mathrm{F}$ molar ratio is increased from 0.1 to 0.5 . The higher the concentration of formaldehyde is, the more highly branched the structure is and the lower the volume of pores. This effect can be counteracted by increasing the dilution ratio. An increase in the amount of solvent hinders crosslinkages and the volume of pores is greater. Therefore, the materials obtained have a high porosity in spite of having a $\mathrm{R} / \mathrm{F}$ molar ratio below the stoichiometric value. However, if the $\mathrm{R} / \mathrm{F}$ molar ratio is increased to above 0.5 , i.e., less formaldehyde than the stoichiometrically required amount, the structure is weakly branched and shrinks during drying. If, in addition, the precursor solutions contain a large amount of solvent and therefore a high dilution ratio, the structure will undergo further contractions during drying, leading to poorly developed porous materials.

It is now clear that the $\mathrm{pH}$, the dilution ratio and the resorcinol-formaldehyde molar ratio have a significant effect on the pore structure of carbon xerogels and hence, it seems worthwhile to assess the results from a statistical point of view. However, it is important to look at the results from a practical point of view and estimate the increase in the performance of carbon xerogels required to maximise the number of applications in which these materials can be used. The total pore volume versus the average pore size is shown in Figure 7. In this figure three coloured regions are highlighted. Each colour indicates the materials synthesized from precursor solutions in which: i) different $\mathrm{pH}$ values were used while the dilution ratio and the $\mathrm{R} / \mathrm{F}$ molar ratio were fixed at the most commonly used values in the literature, i. e., 5.7 and 0.5 , respectively, ii) the $\mathrm{pH}$ and the dilution ratio were simultaneously modified while the $\mathrm{R} / \mathrm{F}$ molar ratio was fixed at 0.5 and iii) the three chemical variables were simultaneously modified. 


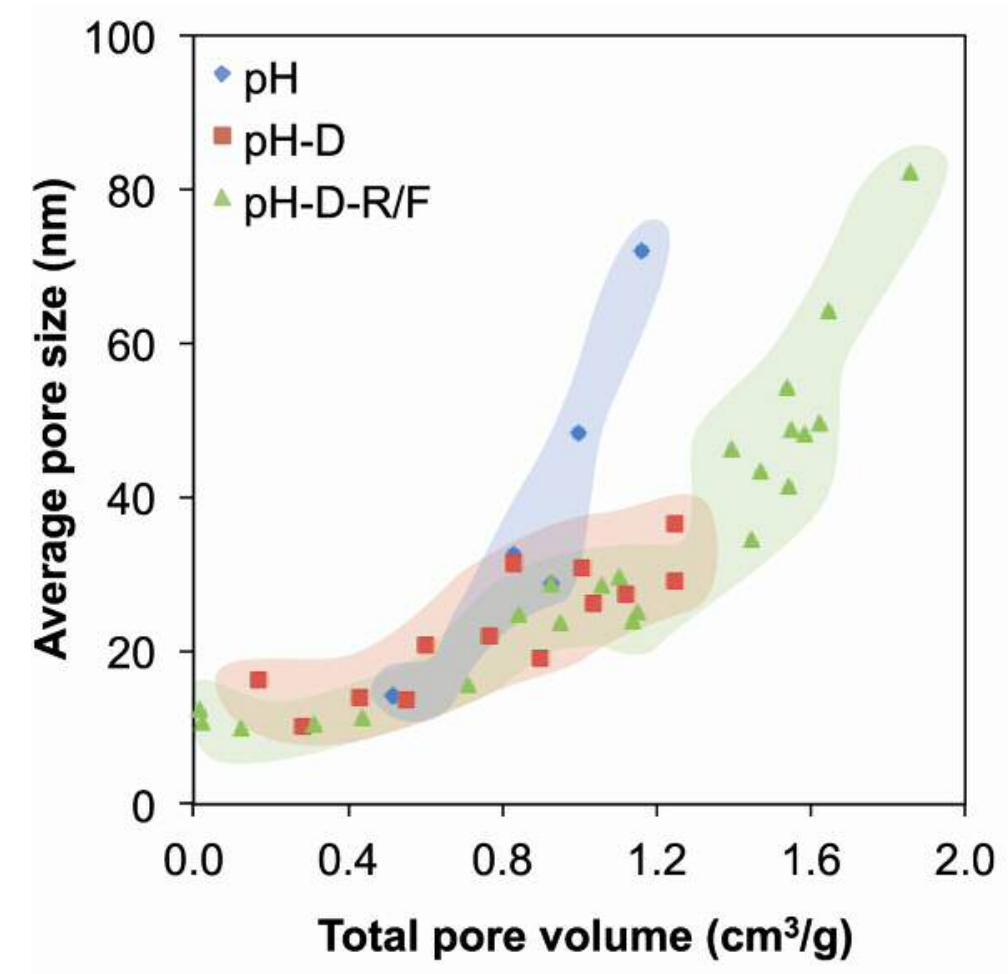

Figure 7 Enhanced pore control in carbon xerogels by modification of the R/F molar ratio

As can be seen from Figure 7, the simultaneous adjustment of the $\mathrm{pH}$, dilution ratio and resorcinol-formaldehyde molar ratio yields carbon xerogels with mean pore sizes that come within the range of pore size required for the majority of applications. Some of these pore sizes can be obtained by just changing the $\mathrm{pH}$ of the precursor solutions together with the dilution ratios. Moreover, by varying the $\mathrm{R} / \mathrm{F}$ molar ratio it is possible to obtain materials with $40 \%$ higher pore volumes, with the result that a more accurate control of the final porous properties can be achieved.

\section{Conclusions}

Statistical analysis has been applied to the micropore, mesopore and macropore volume, and porosity of carbon xerogels. It was found that by modifying simultaneously the $\mathrm{pH}$, the dilution ratio and the resorcinol-formaldehyde molar ratio, it is possible to 
synthesize materials with pore volumes and average pore sizes that cannot be obtained by modifying just the $\mathrm{pH}$ of the precursor solution or the $\mathrm{pH}$ together with the dilution ratio. It has been demonstrated that the resorcinol-formaldehyde molar ratio plays an important role in the microwave-assisted synthesis of carbon xerogels and therefore, by controlling this chemical variable, the performance of carbon xerogels can be enhanced.

It was observed that the micropore volume not only depends on the conditions of the carbonization process, but also varies depending on the resorcinol-formaldehyde molar ratio. A decrease in the value of this variable increases the micropore volume due to the fact that the excess of formaldehyde promotes the formation and growth of the clusters and creates more interconnections between them but also due to the elimination of unreacted formaldehyde during drying leaving new microporosity in the carbon gel structure. The mesopore volume is also increased due to a decrease in the resorcinolformaldehyde molar ratio and to reactions that take place during the carbonization process. On the other hand, the macropore volume depends almost exclusively on the $\mathrm{pH}$ of the precursor mixture within the range of combination of $\mathrm{pH}-\mathrm{D}-\mathrm{R} / \mathrm{F}$ studied.

By applying statistical analysis to the experimental results it is possible to predict the values of the final porous properties within the range of combinations of $\mathrm{pH}-\mathrm{D}-\mathrm{R} / \mathrm{F}$ studied. Hence, carbon xerogels can be directly synthesised and tailored to have porous properties that fit specific application requirements.

\section{Acknowledgements}


Financial support from the Ministerio de Economía y Competitividad of Spain MINECO (under Projects MAT2011-23733 and IPT-2012-0689-420000) is greatly acknowledged. NRR is also grateful to MINECO for her predoctoral research grant.

\section{References}

[1] Pekala RW. Organic aerogels from the polycondensation of resorcinol with formaldehyde. J Mater Sci 1989; 24 (9): 3221-7.

[2] Elkhatat AM, Al-Muhtaseb SA. Advances in tailoring resorcinol-formaldehyde organic and carbon gels. Adv Mater 2011; 23 (26): 2887-903.

[3] Czakkel O, Marthi K, Geissler E, László K. Influence of drying on the morphology of resorcinol-formaldehyde-based carbon gels. Microporous and Mesoporous Materials 2005; 86 (1-3): 124-33.

[4] Léonard A, Job N, Blacher S, Pirard J-P, Crine M, Jomaa W. Suitability of convective air drying for the production of porous resorcinol-formaldehyde and carbon xerogels. Carbon 2005; 43 (8): 1808-11.

[5] Yamamoto T, Nishimura T, Suzuki T, Tamon H. Control of mesoporosity of carbon gels prepared by sol-gel polycondensation and freeze drying. J Non-Cryst Solids 2001; 288 (1-3): 46-55.

[6] Liang C, Sha G, Guo S. Resorcinol-formaldehyde aerogels prepared by supercritical acetone drying. J Non-Cryst Solids 2000; 271 (1-2): 167-70.

[7] Aegerter MA, Leventis N, Koebel MM. Aerogels handbook: Springer; 2011.

[8] Job N, Théry A, Pirard R, Marien J, Kocon L, Rouzaud JN, et al. Carbon aerogels, cryogels and xerogels: Influence of the drying method on the textural properties of porous carbon materials. Carbon 2005; 43 (12): 2481-94. 
[9] Moreno-Castilla C, Maldonado-Hódar FJ. Carbon aerogels for catalysis applications: An overview. Carbon 2005; 43 (3): 455-65.

[10] Moreno AH, Arenillas A, Calvo EG, Bermúdez JM, Menéndez JA. Carbonisation of resorcinol-formaldehyde organic xerogels: Effect of temperature, particle size and heating rate on the porosity of carbon xerogels. J Anal Appl Pyrolysis 2013; 100: 111-6. [11] Pérez-Caballero F, Peikolainen AL, Uibu M, Kuusik R, Volobujeva O, Koel M. Preparation of carbon aerogels from 5-methylresorcinol-formaldehyde gels. Microporous and Mesoporous Materials 2008; 108 (1-3): 230-6.

[12] Horikawa T, Hayashi J, Muroyama K. Size control and characterization of spherical carbon aerogel particles from resorcinol-formaldehyde resin. Carbon 2004; 42 (1): 169-75.

[13] Feng J, Zhang C. Shrinkage and pore structure in preparation of carbon aerogels. J Sol-Gel Sci Technol 2011; 59 (2): 371-81.

[14] Contreras MS, Páez CA, Zubizarreta L, Léonard A, Blacher S, Olivera-Fuentes $\mathrm{CG}$, et al. A comparison of physical activation of carbon xerogels with carbon dioxide with chemical activation using hydroxides. Carbon 2010; 48 (11): 3157-68.

[15] Job N, Panariello F, Marien J, Crine M, Pirard J-P, Léonard A. Synthesis optimization of organic xerogels produced from convective air-drying of resorcinolformaldehyde gels. J Non-Cryst Solids 2006; 352 (1): 24-34.

[16] Wiener M, Reichenauer G, Scherb T, Fricke J. Accelerating the synthesis of carbon aerogel precursors. J Non-Cryst Solids 2004; 350 (0): 126-30.

[17] Rey-Raap N, Menéndez JA, Arenillas A. Optimization of the process variables in the microwave-induced synthesis of carbon xerogels. J Sol-Gel Sci Technol 2013: 1-10. 
[18] Feng Y, Wang J, Ge L, Jiang B, Miao L, Tanemura M. Pore size controllable preparation for low density porous nano-carbon. J Nanosci Nanotechnol 2013; 13 (10): 7012-5.

[19] Pekala RW, Schaefer DW. Structure of organic aerogels. 1. Morphology and scaling. Macromolecules 1993; 26 (20): 5487-93.

[20] Tamon H, Ishizaka H, Mikami M, Okazaki M. Porous structure of organic and carbon aerogels synthesized by sol-gel polycondensation of resorcinol with formaldehyde. Carbon 1997; 35 (6): 791-6.

[21] Lin C, Ritter JA. Effect of synthesis PH on the structure of carbon xerogels. Carbon 1997; 35 (9): 1271-8.

[22] Rey-Raap N, Angel Menéndez J, Arenillas A. RF xerogels with tailored porosity over the entire nanoscale. Microporous and Mesoporous Materials 2014; 195 (0): 26675.

[23] Maldonado-Hódar FJ, Ferro-García MA, Rivera-Utrilla J, Moreno-Castilla C. Synthesis and textural characteristics of organic aerogels, transition-metal-containing organic aerogels and their carbonized derivatives. Carbon 1999; 37 (8): 1199-205.

[24] Gao P, Wang A, Wang X, Zhang T. Synthesis of highly ordered ir-containing mesoporous carbon materials by organic-organic self-assembly. Chem Mater 2008; 20 (5): $1881-8$.

[25] Fairén-Jiménez D, Carrasco-Marín F, Moreno-Castilla C. Porosity and surface area of monolithic carbon aerogels prepared using alkaline carbonates and organic acids as polymerization catalysts. Carbon 2006; 44 (11): 2301-7.

[26] Horikawa T, Hayashi J, Muroyama K. Controllability of pore characteristics of resorcinol-formaldehyde carbon aerogel. Carbon 2004; 42 (8-9): 1625-33. 
[27] Al-Muhtaseb SA, Ritter JA. Preparation and properties of resorcinolformaldehyde organic and carbon gels. Adv Mater 2003; 15 (2): 101-14. 


\section{Simultaneous adjustment of the main chemical variables to fine-tune the porosity}

\section{of carbon xerogels}

Natalia Rey-Raap, J. Angel Menéndez, Ana Arenillas*

Instituto Nacional del Carbón, CSIC, Apartado 73, 33080 Oviedo, Spain

\section{SUPPORTING INFORMATION}

Table S1. ANOVA data for the cubic model applied to the micropore volume

\begin{tabular}{|c|c|c|c|c|c|c|}
\hline \multirow[b]{2}{*}{ Source } & \multicolumn{3}{|c|}{ Degrees of } & \multirow[b]{2}{*}{ F value } & \multirow[b]{2}{*}{ p-value } & \multirow[b]{3}{*}{ Significant } \\
\hline & Sum of squares & eedom & Mean square & & & \\
\hline Model & 0.4000 & 19 & 0.0210 & 6.34 & $<0.0001$ & \\
\hline $\mathrm{pH}$ & 0.0001 & 1 & 0.0001 & 0.02 & 0.8794 & \\
\hline $\mathrm{D}$ & 0.0037 & 1 & 0.0037 & 1.12 & 0.2975 & \\
\hline $\mathrm{R} / \mathrm{F}$ & 0.0072 & 1 & 0.0072 & 2.19 & 0.1490 & \\
\hline $\mathrm{pH}-\mathrm{D}$ & 0.0022 & 1 & 0.0022 & 0.68 & 0.4164 & \\
\hline $\mathrm{pH}-\mathrm{R} / \mathrm{F}$ & 0.0019 & 1 & 0.0019 & 0.59 & 0.4475 & \\
\hline $\mathrm{D}-\mathrm{R} / \mathrm{F}$ & 0.0001 & 1 & 0.0001 & 0.03 & 0.8620 & \\
\hline $\mathrm{pH}^{2}$ & 0.0088 & 1 & 0.0088 & 2.69 & 0.1106 & \\
\hline $\mathrm{D}^{2}$ & 0.0017 & 1 & 0.0017 & 0.51 & 0.4817 & \\
\hline $\mathrm{R} / \mathrm{F}^{2}$ & 0.0323 & 1 & 0.0323 & 9.84 & 0.0036 & Significant \\
\hline $\mathrm{pH}-\mathrm{D}-\mathrm{R} / \mathrm{F}$ & 0.0088 & 1 & 0.0088 & 2.68 & 0.1112 & \\
\hline $\mathrm{pH}^{2}-\mathrm{D}$ & 0.0024 & 1 & 0.0024 & 0.73 & 0.3979 & \\
\hline $\mathrm{pH}^{2}-\mathrm{R} / \mathrm{F}$ & 0.0001 & 1 & 0.0001 & 0.02 & 0.8800 & \\
\hline $\mathrm{pH}-\mathrm{D}^{2}$ & 0.0001 & 1 & 0.0001 & 0.04 & 0.8464 & \\
\hline
\end{tabular}




\begin{tabular}{c|ccccc|c}
\hline $\mathrm{pH}-\mathrm{R} / \mathrm{F}^{2}$ & 0.0135 & 1 & 0.0135 & 4.12 & 0.0507 & \\
$\mathrm{D}^{2}-\mathrm{R} / \mathrm{F}$ & 0.0049 & 1 & 0.0049 & 1.49 & 0.2319 & \\
$\mathrm{D}-\mathrm{R} / \mathrm{F}^{2}$ & 0.0241 & 1 & 0.0241 & 7.35 & 0.0107 & Significant \\
$\mathrm{pH}^{3}$ & 0.0102 & 1 & 0.0102 & 3.11 & 0.0876 & \\
$\mathrm{D}^{3}$ & 0.0003 & 1 & 0.0003 & 0.09 & 0.7615 & \\
$\mathrm{R} / \mathrm{F}^{3}$ & 0.0031 & 1 & 0.0031 & 0.95 & 0.3381 & \\
\hline
\end{tabular}


Table S2. ANOVA data for the cubic model applied to the mesopore volume

\begin{tabular}{|c|c|c|c|c|c|c|}
\hline Source & Sum of squares & $\begin{array}{l}\text { Degrees of } \\
\text { freedom }\end{array}$ & Mean square & F value & p-value & \\
\hline Model & 3.5365 & 19 & 0.1861 & 2.61 & 0.0086 & Significant \\
\hline $\mathrm{pH}$ & 0.0049 & 1 & 0.0049 & 0.07 & 0.7960 & \\
\hline $\mathrm{D}$ & 0.0965 & 1 & 0.0965 & 1.35 & 0.2538 & \\
\hline $\mathrm{R} / \mathrm{F}$ & 0.6636 & 1 & 0.6636 & 9.30 & 0.0047 & Significant \\
\hline pH-D & 0.1895 & 1 & 0.1895 & 2.66 & 0.1133 & \\
\hline $\mathrm{pH}-\mathrm{R} / \mathrm{F}$ & 0.0590 & 1 & 0.0590 & 0.83 & 0.3702 & \\
\hline $\mathrm{D}-\mathrm{R} / \mathrm{F}$ & 0.2563 & 1 & 0.2563 & 3.59 & 0.0675 & \\
\hline $\mathrm{pH}^{2}$ & 0.5133 & 1 & 0.5133 & 7.19 & 0.0116 & Significant \\
\hline $\mathrm{D}^{2}$ & 0.1059 & 1 & 0.1059 & 1.48 & 0.2324 & \\
\hline $\mathrm{R} / \mathrm{F}^{2}$ & 0.0412 & 1 & 0.0412 & 0.58 & 0.4528 & \\
\hline $\mathrm{pH}-\mathrm{D}-\mathrm{R} / \mathrm{F}$ & 0.0049 & 1 & 0.0049 & 0.07 & 0.7960 & \\
\hline $\mathrm{pH}^{2}-\mathrm{D}$ & 0.0758 & 1 & 0.0758 & 1.06 & 0.3107 & \\
\hline $\mathrm{pH}^{2}-\mathrm{R} / \mathrm{F}$ & 0.1115 & 1 & 0.1115 & 1.56 & 0.2206 & \\
\hline $\mathrm{pH}-\mathrm{D}^{2}$ & 0.0883 & 1 & 0.0883 & 1.24 & 0.2744 & \\
\hline $\mathrm{pH}-\mathrm{R} / \mathrm{F}^{2}$ & 0.0051 & 1 & 0.0051 & 0.07 & 0.7908 & \\
\hline$D^{2}-R / F$ & 0.1307 & 1 & 0.1307 & 1.83 & 0.1857 & \\
\hline $\mathrm{D}-\mathrm{R} / \mathrm{F}^{2}$ & 0.0401 & 1 & 0.0401 & 0.56 & 0.4589 & \\
\hline $\mathrm{pH}^{3}$ & 0.6921 & 1 & 0.6921 & 9.70 & 0.0040 & Significant \\
\hline $\mathrm{D}^{3}$ & 0.2452 & 1 & 0.2452 & 3.44 & 0.0733 & \\
\hline $\mathrm{R} / \mathrm{F}^{3}$ & 0.1370 & 1 & 0.1370 & 1.92 & 0.1757 & \\
\hline
\end{tabular}


Table S3. ANOVA data for the cubic model applied to the macropore volume

\begin{tabular}{|c|c|c|c|c|c|c|}
\hline Source & Sum of squares & $\begin{array}{l}\text { Pegrees of } \\
\text { freedom }\end{array}$ & Mean square & F value & p-value & \\
\hline Model & 19.7993 & 19 & 1.0421 & 2.90 & 0.0082 & Significant \\
\hline $\mathrm{pH}$ & 6.6686 & 1 & 6.6686 & 18.55 & 0.0003 & Significant \\
\hline $\mathrm{D}$ & 1.5090 & 1 & 1.5090 & 4.20 & 0.0521 & \\
\hline $\mathrm{R} / \mathrm{F}$ & 0.6723 & 1 & 0.6723 & 1.87 & 0.1847 & \\
\hline pH-D & 0.3861 & 1 & 0.3861 & 1.07 & 0.3109 & \\
\hline $\mathrm{pH}-\mathrm{R} / \mathrm{F}$ & 0.0036 & 1 & 0.0036 & 0.01 & 0.9217 & \\
\hline $\mathrm{D}-\mathrm{R} / \mathrm{F}$ & 0.3189 & 1 & 0.3189 & 0.89 & 0.3561 & \\
\hline $\mathrm{pH}^{2}$ & 0.0070 & 1 & 0.0070 & 0.02 & 0.8902 & \\
\hline $\mathrm{D}^{2}$ & 0.3401 & 1 & 0.3401 & 0.95 & 0.3409 & \\
\hline $\mathrm{R} / \mathrm{F}^{2}$ & 1.4936 & 1 & 1.4936 & 4.15 & 0.0532 & \\
\hline $\mathrm{pH}-\mathrm{D}-\mathrm{R} / \mathrm{F}$ & 0.0484 & 1 & 0.0484 & 0.13 & 0.7169 & \\
\hline $\mathrm{pH}^{2}-\mathrm{D}$ & 0.3176 & 1 & 0.3176 & 0.88 & 0.3571 & \\
\hline $\mathrm{pH}^{2}-\mathrm{R} / \mathrm{F}$ & 0.0027 & 1 & 0.0027 & 0.01 & 0.9312 & \\
\hline $\mathrm{pH}-\mathrm{D}^{2}$ & 1.4619 & 1 & 1.4619 & 4.07 & 0.0556 & \\
\hline $\mathrm{pH}-\mathrm{R} / \mathrm{F}^{2}$ & 0.3609 & 1 & 0.3609 & 1.00 & 0.3268 & \\
\hline $\mathrm{D}^{2}-\mathrm{R} / \mathrm{F}$ & 0.4435 & 1 & 0.4435 & 1.23 & 0.2782 & \\
\hline $\mathrm{D}-\mathrm{R} / \mathrm{F}^{2}$ & 0.0017 & 1 & 0.0017 & 0.00 & 0.9463 & \\
\hline $\mathrm{pH}^{3}$ & 0.2415 & 1 & 0.2415 & 0.67 & 0.4209 & \\
\hline $\mathrm{D}^{3}$ & 0.2240 & 1 & 0.2240 & 0.62 & 0.4380 & \\
\hline $\mathrm{R} / \mathrm{F}^{3}$ & 0.3864 & 1 & 0.3864 & 1.07 & 0.3107 & \\
\hline
\end{tabular}


Table S4. ANOVA data for the quadratic model applied to the porosity

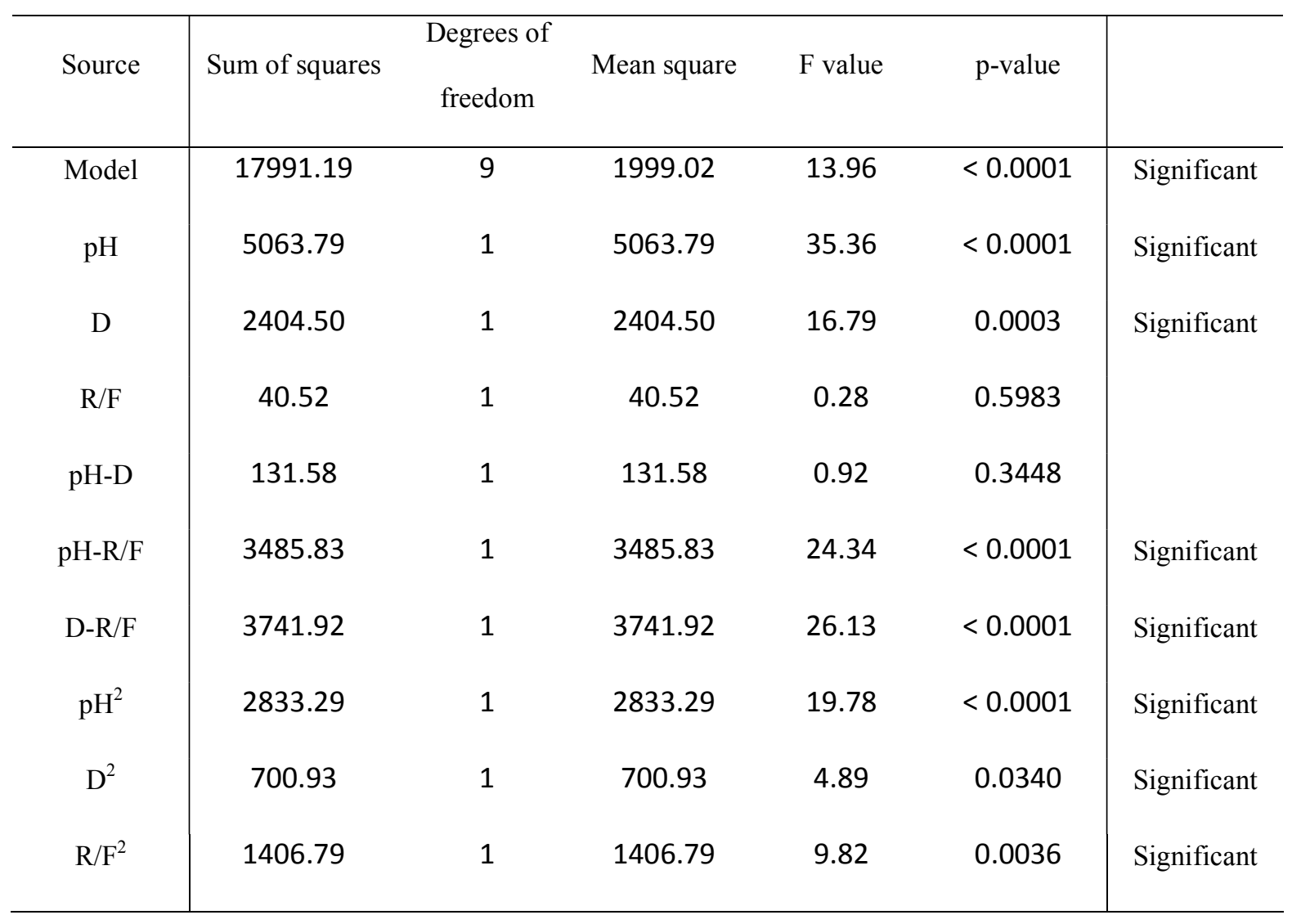

